\title{
Enduring feedback
}

Etiënne A. J. A. Rouwette

\section{E.Rouwette@fm.ru.nl}

Tel +31 (0)243611468

Email E.Rouwette@fm.ru.nl

Institute for Management Research

Nijmegen School of Management, Radboud University

P.O. Box 9108

6500 HK Nijmegen

The Netherlands

Abstract

The central question in the paper by Morecroft (2017) is whether 'structure drives behaviour' also holds over a long time period, or, in other words, whether feedback structures shaping trends endure over time. Morecroft revisits a model of the oil industry originally developed in the late 1980s and, changing only initial parameter settings, concludes that the model is able to represent recent developments. The Limits to Growth model is another example of a feedback structure that can explain behaviour over decennia. The finding that feedback structure is enduring is good news for system dynamicists and increases our confidence in one of the field's central assumptions. This paper discusses the modelling effort described from two perspectives: the process leading up to the final model structure and the wider implications of models that address long term real life problems, in particular for the field of system dynamics.

\section{Introduction}

The central question in the paper by Morecroft (2017) is whether 'structure drives behaviour' also holds over a long time period, or, in other words, if feedback structures shaping trends endure over time. The paper starts by describing the behaviour of the oil price from 1869 to 2011. It then outlines the developments in the oil industry underlying long-term behaviour, with a particular emphasis on the emergence of OPEC in the 1970s. The structure responsible for recent oil price behaviour is explained in more depth, using five main sectors: independent producers, the swing producer, opportunists, OPEC quota setting and market price and demand. This structure resulted from initial model development in 1988-1989 with a team from Shell and intermediate model updates in the mid1990s and again in 2014 (Morecroft, 2015; Morecroft \& Heijden, 1992). The resulting model is used to understand the impact of the rise of shale oil from 2008 onwards. The model is updated and initialized in 2010 with (compared to the original model) a higher level of independents' undeveloped reserves, higher independents' capacity that is also growing at a higher rate, and a moderate economic growth. Morecroft explicitly addresses the place of technology in the model structure. In line with model purpose, technology is captured as a reduction of development cost per barrel over time. This, in turn, 
makes more investment and production possible compared to a situation in which technology has not improved. Other models capture technology in more depth and make it part of the endogenous structure (see Brandt, 2010 for an overview of mathematical models in the oil sector). Model behaviour for the period 2010-2034 is described and its drivers are explained. The model is also used to test the Saudi America hypothesis, the idea that the United States will replace Saudi Arabia as the swing producer. The conclusion is that the structure driving the oil industry has not changed. This structure includes both the investment policies by different producer groups as well as the types of resources each has access too: vast reserves of low-cost oil in the case of the OPEC countries, medium-cost fields in the case of independents such as Russia, and tight, high-cost reserves for US-based shale producers.

Morecroft goes on to describe another example of enduring feedback structures, the World dynamics (Forrester, 1971) and Limits to Growth (Meadows, Meadows, Randers, \& Behrens III, 1972; Meadows, Randers, \& Meadows, 2004) models. Turner (2008) shows that historical data for 1970-2000 are in line with the business as usual scenario called the 'standard run' in Limits to Growth.

Thus, in hindsight we can conclude that it is possible to develop system dynamics (SD) models that capture the feedback structure that shape behaviour over the course of 30 or more years, as both the oil producers' and Limits to Growth projects show. Which other important lessons can we learn from these two examples? The remainder of this paper will discuss one lesson on the level of the modelling process. The second lesson is on the more generic level of the field of system dynamics.

The iterative modelling process

The oil producers' and Limits to Growth models have a number of similarities in terms of the modelling process. The structure of both models was built with domain experts, meaning that the modeller could draw on extensive knowledge of the issues being studied. Model structure was developed in an iterative fashion, in the case of Limits to Growth leading to Forrester's 1971 book (Forrester, 1971), Limits to Growth in 1972 and the 30 year update in 2004 (Meadows et al., 1972; Meadows et al., 2004). Morecroft (2017) shows how his model has also gone through two major updates. Both modelling processes are in line with what Homer (1996) describes as good practice in scientific modelling. 'Indeed, one might say that every system dynamics model goes through an early exploratory stage in which some hypotheses are formulated with little or no empirical foundation' (Homer, 1996: 1). Exploration then gives way to replication of reference modes, and later to a focus on robustness, flexibility and clarity. This may mean that the model is revised in terms of system boundary, level of aggregation, and detail of formulation. Morecroft's (2017) discussion on the role of technological innovation in the oil producer's model is an example of decisions a modeller needs to make when developing his or her model further. Homer also talks about finding, accessing and analysing data as necessary steps that a modeller needs to take. Limits to Growth has come under scrutiny in this respect and the fact that an analysis of new data was published in 2008 (Turner, 2008) reflects Homer's concern with data.

\section{Topics for modelling}

The teams of modellers responsible for developing the oil producers' and Limits to Growth models had a close connection to experts in their respective domains. Direct advantages of this are access to information relevant to model structure and to data, as well as a higher chance of influencing actual decision making (e.g. Roberts, 1977). Over the years, system dynamics has built up a track record of 
working on real life client problems (see www.cases.systemdynamics.org). By now, many reports of client applications are available in which system dynamics modelling has helped to clarify real world issues and identify policies. Some reports also provide evidence on improvements in societal or commercial issues due to implementation of these policies.

However, a large role of clients in driving modelling endeavours has at least two unintended and possibly negative consequences. The first is an inductive, person-dependent way of choosing modelling topics instead of an approach resembling a research program addressing major societal or scientific problems. A devil's advocate may say that the choice of topics to be modelled is driven more by the networks of experienced system dynamicists than by a conscious choice based on today's most important topics. Surely this is an exaggeration as modelling work is continuously being done on major issues concerning health, safety, energy and food. This is evidenced by the annual System dynamics conference in which threads cover these, as well as other, topics every year. But it is also true that more could be done in showing the unique contributions that system dynamics has to offer to each of these domains. Eskinasi (2014), who has spent a significant part of his career in the housing sector, observes that system dynamicists frequently switch from one domain to the other in a relatively short time. They identify the problems most amenable to a feedback perspective, capture these in one or a small set of models, and move on. When engaging longer with a particular domain it becomes possible to see better where SD offers benefits over methods traditionally used in that field, and become a partner in ongoing discussions. He argues for an 'embedded' form of system dynamics. In this form of modelling, system dynamics is used together with other social sciences methodologies (a mixedmethod approach) and grounded in the theories and empirical findings of the respective field of application. Another element of making system dynamics more than a series of models on diverse albeit important - issues is the aggregation of insights. Forrester (e.g. 2007) has urged system dynamicists to model of a class of problems, not one specific instance. In the past, modelling insights have been aggregated in the form of canonical situation models (Forrester, Legasto, \& Lyneis, 1980; Lane, 1998), abstracted micro structures (Lane, 1998), and archetypes (Senge, 1990; Wolstenholme, 2003). At a less aggregate level we find concepts such as the capability trap. Companies falling into this trap invest in capabilities with a quick return instead of those that take time to pay off (e.g. Rahmandad, 2015). Across a wide range of industries companies are prone to fall into the capability trap: they invest in launching a new software product faster rather than in testing new tools, in reactive rather than proactive maintenance. These concepts are powerful in the sense that they crystallise the insights gained in a number of specific modelling projects and (more than insights from a specific project) are likely to inform theory. The capability trap for instance builds on the resource-based view of the firm (Rahmandad, 2015). However, again drawing on experiences at the annual conferences, applications to specific issues outnumber attempts to aggregate insights by far.

The connection to theory raises another point. A second negative consequence of clients driving the selection of modelling topics is that system dynamics models on problems of theoretical interest are relatively scarce. De Gooyert (2016) conducts a literature analysis of system dynamics publications in top management journals between 1990 and 2016 and finds 25 articles. About 450 papers and posters are presented annually at the System Dynamics Conference. The System Dynamics Review published 12 full articles in 2016 (Executive editor report) and an unknown number of articles appeared in other journals. By comparison, 25 articles in 26 years seem rather low. In combination, could the predominance of client-driven topics and lack of theoretical focus help to explain the relatively low representation of system dynamics in management journals? The apparent stagnation of the field has been discussed for some time (e.g. Forrester, 2007; Grossler, 2013; Homer, 2013). The discussion has centred on the lack of focus on important problems, the quality of system dynamics work, the 
education program and the diversity of the field, among others. The lack of theoretical focus may be added to the list of possible explanations for the low growth of the field.

\section{Conclusion}

Some of the best work that system dynamics has to offer is the rigorous analysis of real world problems, resulting in structural explanations for problems that in some cases endure over decades. Morecroft (2017) describes the oil producers' microworld as an example of enduring feedback structure. This discussant paper raised two points on this type of models. The first concerned the modelling process. It is striking that both the oil producers' microworld and Limits to Growth have been developed in close collaboration with domain experts. Both modelling efforts also follow an iterative approach characteristic of scientific modelling (Homer, 1996). The second point addressed the wider implications of these models. Applying system dynamics to real world problems shows the strengths of the feedback approach and leads to wider recognition of the field. But there are also advantages to working in a particular domain for an extended period, as it raises awareness of ongoing discussions in that field and clarifies where system dynamics is complementary to methods commonly used. Attempts to integrate insights beyond specific client problems are relatively scarce. In addition, the focus on real world problems may come at the cost of theory-oriented work.

System dynamicists regularly marvel at the lack of recognition for the field, as clearly, the system dynamics approach is so relevant to many of today's problems. Doing good work on relevant issues is surely the basis for the growth of any scientific field. A number of ways have been suggested to grow the field faster. This discussion paper suggests two additional approaches: engaging with a domain for a longer time and devoting more attention to theoretical issues.

\section{References}

Brandt, A. (2010). Review of mathematical models of future oil supply: Historical overview and synthesizing critique. Energy, 35, 3958-3974.

De Gooyert, V. (2016). Nothing so practical as a good theory; Five ways to use system dynamics for theoretical contributions, Delft.

Eskinasi, M. (2014). Towards housing system dynamics. Projects on embedding system dynamics in housing policy research. (PhD), Radboud University, Nijmegen.

Forrester, J. (1971). World dynamics: available from the System Dynamics Society www.systemdynamics.org originally published by Wright-Allen Press, Cambridge, MA.

Forrester, J. (2007). System dynamics - the next fifty years. System Dynamics Review, 23(2-3), 359-370.

Forrester, J., Legasto, A., \& Lyneis, J. (1980). System dynamics: North-Holland Publishing Company.

Grossler, A. (2013). The "aimless plateau": A necessary dilemma between growth and coherent identity? System Dynamics Review, 29(4), 264-266. doi: 10.1002/sdr.1509

Homer, J. B. (1996). Why we iterate: scientific modeling in theory and practice. System Dynamics Review, 12(1), 1-19.

Homer, J. B. (2013). The aimless plateau, revisited: why the field of system dynamics needs to establish a more coherent identity. System Dynamics Review, 29(2), 124-127.

Lane, D. (1998). Can we have confidence in generic structures? Journal of the Operational Research Society, 49(9), 936-947.

Meadows, D., Meadows, D., Randers, J., \& Behrens III, W. (1972). The limits to growth: a report to the club of Rome on the predicament of mankind. New York: Universe Books.

Meadows, D., Randers, J., \& Meadows, D. (2004). Limits to growth: the 30-year update. White River Junction, VT: Chelsea Green Publishing. 
Morecroft, J. (2015). Strategic modelling and business dynamics (Second ed.). Chichester, UK: Wiley. Morecroft, J., \& Heijden, K. v. d. (1992). Modeling the oil producers. Capturing oil industry knowledge in a behavioral simulation model. European Journal of Operational Research, 59, $102-122$.

Rahmandad, H. (2015). Connecting strategy and system dynamics: an example and lessons learned. System Dynamics Review, 31(3), 149-172.

Roberts, E. (1977). Strategies for effective implementation of complex corporate models. TIMS-ORSA Interfaces, 8(1, part 1), 26-33.

Senge, P. M. (1990). The fifth discipline. The art and practice of the learning organization. New York: Doubleday.

Turner, G. (2008). A comparison of The Limits to Growth with 30 years of reality. Global Environmental Change, 18(3), 397-411.

Wolstenholme, E. (2003). Towards the definition and use of a core set of archetypal structures in system dynamics. System Dynamics Review, 19(1), 7-26. 